\title{
Sleeping well with cancer: a systematic review of cognitive behavioral therapy for insomnia in cancer patients
}

This article was published in the following Dove Press journal:

Neuropsychiatric Disease and Treatment

18 June 2014

Number of times this article has been viewed

\author{
Sheila N Garland' \\ Jillian A Johnson ${ }^{2}$ \\ Josee Savard ${ }^{3}$ \\ Philip Gehrman ${ }^{4}$ \\ Michael Perlis ${ }^{4}$ \\ Linda Carlson ${ }^{5}$ \\ Tavis Campbell ${ }^{2}$
}

'Department of Family Medicine and Community Health, University of Pennsylvania, Philadelphia, PA, USA; ${ }^{2}$ Department of Psychology, University of Calgary, Calgary, AB, Canada; ${ }^{3}$ School of Psychology, Laval University, Quebec City, QC, Canada; ${ }^{4}$ Department of Psychiatry, University of Pennsylvania, Philadelphia, PA, USA; ${ }^{5}$ Department of Oncology, University of Calgary, Calgary, AB, Canada
Correspondence: Tavis Campbell Department of Psychology, University of Calgary, 2500 University Drive NW, Calgary, AB, T2N IN4, Canada Email t.s.campbell@ucalgary.ca

\begin{abstract}
Individuals with cancer are disproportionately affected by sleep disturbance and insomnia relative to the general population. These problems can be a consequence of the psychological, behavioral, and physical effects of a cancer diagnosis and treatment. Insomnia often persists for years and, when combined with already high levels of cancer-related distress, may place cancer survivors at a higher risk of future physical and mental health problems and poorer quality of life. The recommended first-line treatment for insomnia is cognitive behavioral therapy for insomnia (CBT-I), a non-pharmacological treatment that incorporates cognitive and behavior-change techniques and targets dysfunctional attitudes, beliefs, and habits involving sleep. This article presents a comprehensive review of the literature examining the efficacy of CBT-I on sleep and psychological outcomes in cancer patients and survivors. The search revealed 12 studies (four uncontrolled, eight controlled) that evaluated the effects of CBT-I in cancer patients or survivors. Results suggest that CBT-I is associated with statistically and clinically significant improvements in subjective sleep outcomes in patients with cancer. CBT-I may also improve mood, fatigue, and overall quality of life, and can be successfully delivered through a variety of treatment modalities, making it possible to reach a broader range of patients who may not have access to more traditional programs. Future research in this area should focus on the translation of evidence into clinical practice in order to increase awareness and access to effective insomnia treatment in cancer care.
\end{abstract}

Keywords: CBT-I, cancer, insomnia, sleep, systematic review, quality of life, survivors

\section{Background \\ Prevalence of sleep disturbances and insomnia in cancer}

Cancer is one of the leading causes of global morbidity and mortality, second only to heart disease. ${ }^{1}$ The global burden of cancer is expected to reach 21.4 million individuals by $2030 .{ }^{2}$ Since the early 1990 s, early detection and improved treatment methods have led to an overall reduction in cancer death rates and the prevention of approximately 1,024,400 cancer deaths. ${ }^{3}$ Improved survival rates mean that more people will require ongoing treatment for the persistent physical and psychological side effects of a cancer diagnosis. An important but often overlooked side effect of cancer diagnosis and treatment is sleep disturbance and insomnia. ${ }^{4-7}$ Prevalence rates for insomnia in individuals with cancer range from $30 \%$ to $60 \%$, depending on the definition, time of assessment, and measurement tool used. ${ }^{8-10}$ According to the most recent Diagnostic and Statistical Manual of Mental Disorders, fifth edition, nosology, "insomnia" is defined as dissatisfaction with sleep quality or quantity characterized by difficulty initiating sleep, maintaining sleep, or early morning awakenings that cause significant 
distress or impairment in daytime functioning and occur at least three nights per week for at least 3 months despite adequate opportunity for sleep. ${ }^{11}$ The presence of persistent insomnia places patients at a higher risk for psychological and physical morbidity and reduced quality of life. ${ }^{12,13}$

\section{Chemotherapy as a contributor to disturbed sleep and insomnia}

The greater rate of insomnia experienced by cancer patients has not only been attributed to the emotional consequences of being diagnosed with cancer but also to the direct effects of cancer treatments and their side effects, particularly chemotherapy. ${ }^{7,16}$ In a prospective study of 823 patients undergoing chemotherapy, 39.8\% reported moderate or severe insomnia symptoms after their first chemotherapy treatment, with symptoms persisting throughout subsequent cycles in two-thirds of patients. ${ }^{5}$ A systematic review of 21 articles further suggested that sleep disturbances can persist for up to 1 year post-chemotherapy. ${ }^{17}$ The most commonly reported sleep problem by patients undergoing chemotherapy is the inability to maintain sleep (63.3\%), with disruptions being attributed to the anxiety and worry related to the cancer diagnosis/treatments and the effects of cancer treatments themselves (ie, postsurgical pain/discomfort, overall fatigue, nausea, nocturnal hot flashes, increased bathroom use, and steroid-induced agitation). ${ }^{18-20}$ As such, it appears that cancer treatments, particularly chemotherapy and surgery, may contribute to an increased risk for developing clinically significant sleep disturbances and partially account for the higher than average prevalence rates demonstrated in this population.

\section{Disturbed sleep, insomnia, and other cancer consequences}

Sleep disturbances and insomnia frequently co-occur in symptom clusters with other commonly reported cancer side effects, such as pain, fatigue, psychological distress, and depression. ${ }^{21-23}$ Although the mechanisms involved are not completely understood, the presence of symptom comorbidity in cancer patients might relate to underlying inflammatory processes common to many of these concerns. ${ }^{24}$ This may partially explain why these symptoms have demonstrated both indirect and direct reciprocal effects; that is, the presence of one influences the incidence and severity of the others. ${ }^{25}$ A recent study investigated the relationship between sleep difficulty, self-reported pain, and emotional distress in a sample of 2,862 cancer outpatients. ${ }^{26}$ Individuals reporting clinically significant pain were 2.7 times more likely to experience sleep difficulty than those without pain, whereas people with higher levels of emotional distress were 4.5 times more likely to report problems with sleep than those with low distress levels. Considering that sleep disturbance co-occurs with, and significantly contributes to, other cancer-related symptoms, it may be important for interventions to address symptom clusters or to focus on the symptom most associated with the other conditions.

\section{Disturbed sleep, insomnia, and quality of life}

Not only are cancer-related sleep disturbances widespread representing a major concern for people irrespective of their stage in the cancer trajectory - they can also negatively impact overall quality of life and cancer-therapy outcomes. The relationship between insomnia and quality of life was explored in a cross-sectional analysis of 954 people with a variety of cancer diagnoses. ${ }^{13}$ Regardless of age and treatment status, higher self-reported insomnia symptoms were associated with lower overall quality of life, with particularly strong associations with poorer subjective health/physical and psychological/spiritual well-being. Although not conclusive, there is also evidence that impaired sleep can have a negative impact on objective health outcomes. Mormont et al reported that metastatic colorectal cancer patients with dysregulated sleep/wake patterns (ie, poorly differentiated activity levels during wake and sleep) were five times more likely to die within 5 years than patients with a more distinguishable circadian rhythm. ${ }^{27}$ When assessed using actigraphy, people with a dampened circadian rhythm, characterized by flat profiles with less activity during the day and more activity during the night, reported more depressive symptoms and worse overall quality of life than those with more robust circadian rhythms. ${ }^{28}$ Together, these studies suggest that the maintenance of robust circadian rhythms and consistent and distinguishable sleep and wake patterns have the potential to reduce depressive symptomatology, improve overall perception of quality of life, and potentially translate into better physical outcomes and survival. Although the directionality of these effects is not clear, it is possible that intervening anywhere in the cycle (eg, targeting sleep) may subsequently positively effect other symptoms and longer-term outcomes.

\section{Cognitive behavioral therapy for insomnia (CBT-I)}

Compared with good sleepers, individuals with insomnia exhibit cognitive, physiological, and cortical hyperarousal;29,30 demonstrate particular cognitive patterns 
and attentional biases; $; 1,32$ and strongly endorse problematic sleep-related beliefs. ${ }^{33,34}$ Cognitive behavioral therapy for insomnia (CBT-I) is a multicomponent intervention developed to address these interrelated components. Essentially, CBT-I has five potential components: sleep restriction, stimulus control, sleep hygiene, cognitive restructuring, and relaxation training. ${ }^{35}$ Most modern studies of CBT-I include sleep restriction and stimulus control. "Sleep restriction" addresses what is believed to be the primary perpetuating factor for chronic insomnia - the mismatch between sleep opportunity and sleep ability. "Stimulus control" targets stimulus "dyscontrol" (the occurrence of a diversity of non-sleep behaviors in the bedroom $)^{36}$ and sets the stage for counterconditioning (ie, the reconditioning of sleeprelated stimuli to elicit the physiology of sleep as opposed to the physiology of wakefulness). "Sleep hygiene", while ineffective as a monotherapy, serves to promote behaviors and practices that facilitate sleep and to discourage those that are thought to contribute to insomnia. ${ }^{37}$ "Cognitive restructuring" is used to identify and address thoughts and beliefs that may contribute to the development of, or reinforce, behaviors that produce pre-sleep arousal and/ or performance anxiety. Relaxation training (the original behavioral intervention for insomnia) is no longer regularly incorporated into CBT-I but is sometimes utilized to reduce peripheral autonomic arousal and facilitate mental de-arousal..$^{38}$

\section{Evidence for the overall efficacy of CBT-I}

CBT-I, with or without relaxation therapy, is recommended by the American Association of Sleep Medicine, is considered a well-established intervention by the American Psychiatric Association, ${ }^{39}$ and has demonstrated efficacy for treating primary insomnia. ${ }^{40,41}$ In non-cancer groups, CBT-I has produced larger effects than treatment as usual (TAU), ${ }^{42}$ waitlist control groups ${ }^{43,44}$ pharmacotherapy $+/$ - medication placebo, ${ }^{45-49}$ relaxation therapy and behavioral placebo, ${ }^{50,51}$ and sleep-hygiene education. ${ }^{52} \mathrm{Of}$ the studies with long-term follow-ups, the effects of CBT-I have been remarkably durable (up to 2 years time) in a substantial proportion of participants, and, on several measures, patients continue to improve (if not reach remission) long after treatment is discontinued. ${ }^{53}$ While most of the treatment evaluation investigations utilize a form of CBT-I that is in person, one-on-one, and extends over five to ten sessions, there is evidence that CBT-I can be successfully delivered to groups,${ }^{54,55}$ by telephone, ${ }^{56}$ over the Internet, ${ }^{57}$ and with self-help manuals.$^{58}$ Finally, there is an emerging literature providing clear demonstrations that insomnia comorbid with psychiatric or medical disorders is as responsive, if not more so, to CBT-I than so-called primary insomnia. ${ }^{52,59}$ Several of these trials have also shown that CBT-I also produces improvements in the comorbid condition. For example, in the context of major depression, CBT-I nearly doubles response and remission rates when added to standard antidepressant therapies. ${ }^{60}$

CBT-I in the context of cancer is thought to be particularly challenging because of the overlap and chronicity of cancer-related side effects that may influence the development, severity, and persistence of insomnia symptoms. The purpose of the present report is to summarize the effect of CBT-I in cancer patients and present recommendations for future research.

\section{Methods}

An independent review of the literature was performed separately by the first and second authors using PubMed, MEDLINE $^{\circledR}$, and PsycINFO databases from the earliest date available until January 2014. Only studies published in English were eligible for review. Search terms included "cancer/neoplasms", "insomnia", "cognitive", "behavioral", "cognitive behavioral therapy", "cognitive therapy", "behavioral therapy", "CBT-I", "CBT", "treatment", "intervention", and "sleep disturbances". Reference lists of the retrieved articles were reviewed and articles in press were identified by contacting the authors directly. An article was included if it met the following three criteria: 1) cognitive behavior therapy or behavior therapy tailored for insomnia was used as the primary treatment, 2) the target population were people diagnosed with cancer (either undergoing or having completed primary treatment), and 3) a subjective or objective measure of sleep was included as a treatment outcome. Once the independent search results were compared, any discrepancies were resolved through consultation with the final author and consensus was achieved. A total of 12 intervention studies met the inclusion criteria: four were quasi-experimental studies (ie, no random assignment to treatment or a control condition) and eight were randomized controlled trials (RCTs). We did not identify any articles of CBT-I in cancer patients published in non-English journals.

\section{Results \\ Quasi-experimental studies of CBT-I in cancer patients}

Four uncontrolled studies investigating CBT-I in cancer patients were identified for inclusion (Table 1). All of these studies were conducted with non-metastatic cancer patients 


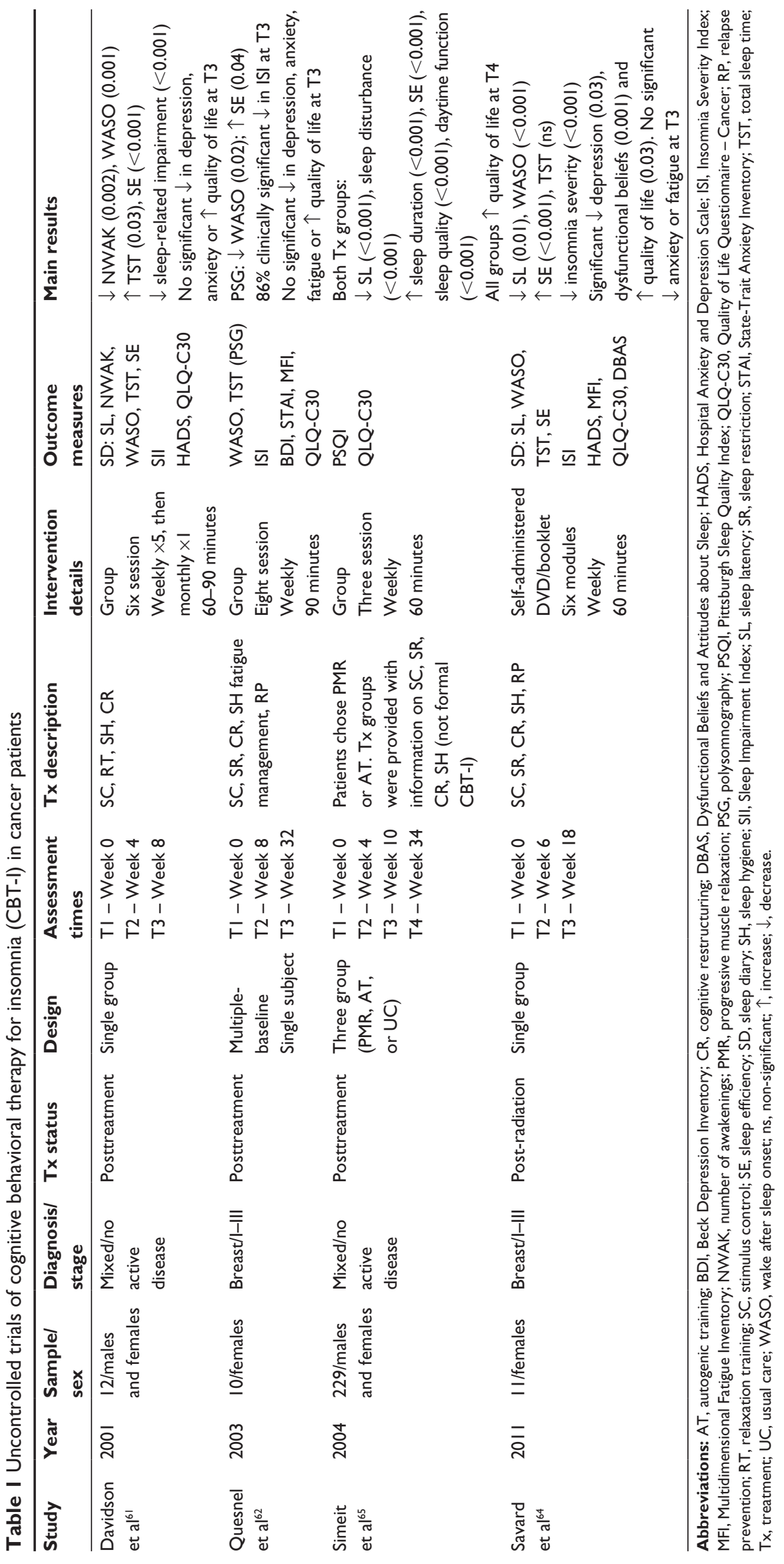


(50\% breast and 50\% mixed diagnoses) who were posttreatment. Davidson et al published the first pre-post study of a 6-week non-pharmacological sleep therapy program using CBT-I components (stimulus control, relaxation, "worry time", and sleep hygiene) to improve sleep quality of a heterogeneous group of 12 breast-cancer patients with insomnia. ${ }^{61}$ Pre- to posttreatment effect sizes ranged from 0.58 for total sleep time to 2.0 for sleep efficiency, indicating a statistically and clinically significant improvement in patient functioning. Quesnel et al were the next to investigate a CBT-I intervention in a sample of ten women with breast cancer in a multiple-baseline design. ${ }^{62}$ At the end of the study, $50 \%$ of the participants met the classification cutoff for "good sleepers", designated as $85 \%$ sleep efficiency. This percentage increased to $71 \%$ at the 6-month follow-up. Although both of these studies were limited by small sample sizes and no comparison groups, they provided impetus for larger efficacy trials.

In-person psychological therapies, like CBT-I, may not always be readily accessible, especially within cancer care ${ }^{63}$ Hence, Savard et al investigated the feasibility of self-administering CBT-I via 6-weekly DVD/booklets in eleven women with breast cancer. ${ }^{64}$ The treatment consisted of standard CBT-I components and was designed to match what would be delivered via face-to-face treatment. Insomnia severity and all sleep-diary variables (except total sleep time) demonstrated significant improvements at posttreatment, and these gains were maintained at the 3-month follow-up. This preliminary study was followed by a three-arm RCT comparing video-delivered and professionally administered CBT-I to a no-treatment control group; the results of this are described in the next section.

While CBT-I has largely been standardized in its delivery, important questions remain about the adequate "dose" or necessary delivery required to produce treatment effects. Simeit et al incorporated components of CBT-I into a multimodal psychological intervention for 229 inpatients at a cancer rehabilitation clinic. ${ }^{65}$ The two intervention groups chose a preferred relaxation technique (progressive muscle relaxation or autogenic training) and received three standardized psychoeducational sessions that provided information about sleep hygiene, stimulus control, and cognitive restructuring. Both of the intervention groups showed durable improvements in sleep variables compared with the usual care comparison group. These results suggest that providing a modest sleepeducation intervention and relaxation training while patients receive treatment may be an effective way to address acute insomnia and ward off future sleep disturbances; however, definitive prevention trials are required to adequately address this possibility.

\section{Controlled studies of CBT-I in cancer patients}

Eight RCTs of CBT-I in cancer patients were available for review. Two of these trials are reported in separate publications, bringing the number of papers to ten (Table 2). Five of these studies were conducted in samples of women with breast cancer and the remaining three included men and women with mixed cancer diagnoses. The majority of studies $(80 \%)$ were conducted with patients who had completed treatment. Half of the studies consisted of in-person group-based interventions while the other half were individual-based interventions, of which one delivered CBT-I to individuals via the Internet. The intervention length ranged from 5 to 9 weeks, and observed effects tended to be larger in studies that used waitlist or TAU groups rather than attention control groups. Two studies compared CBT-I with another active treatment group.

The largest trial to date of standard CBT-I for insomnia in cancer was conducted in 2008 by Espie et al. ${ }^{66}$ This study assigned 150 heterogeneous posttreatment cancer patients to either a 5-week CBT-I intervention or TAU. The TAU group was intended to represent normal clinical practice, whereby physicians were free to offer appointments and prescribe sedative medications. Statistically and clinically significant improvements in subjective measures of sleep were demonstrated for sleep onset latency, wake after sleep onset, and sleep efficiency in the CBT-I group, with large between-group effect sizes of $-0.86,-0.97$, and 1.09 , respectively. These results translated into a reduction of approximately 1 hour in sleep onset latency and time spent awake during the night compared with no change in the TAU group. These improvements in sleep outcomes were significantly related to increased quality of life and reduced daytime fatigue.

Savard et al investigated the efficacy of CBT-I in a waitlist-controlled trial of 57 women who had received treatment for breast cancer. ${ }^{67,68}$ Outcomes included sleep quantity/ quality (assessed with sleep diaries and polysomnography), psychological distress, ${ }^{67}$ and immune functioning. ${ }^{68}$ Prepost program sleep diaries revealed significant reductions in sleep onset latency and time spent awake at night, and improvements in sleep efficiency. These improvements were mirrored on the polysomnography assessment of sleep. Total sleep time steadily increased over the 12-month study period, with participants averaging an additional 38 minutes 


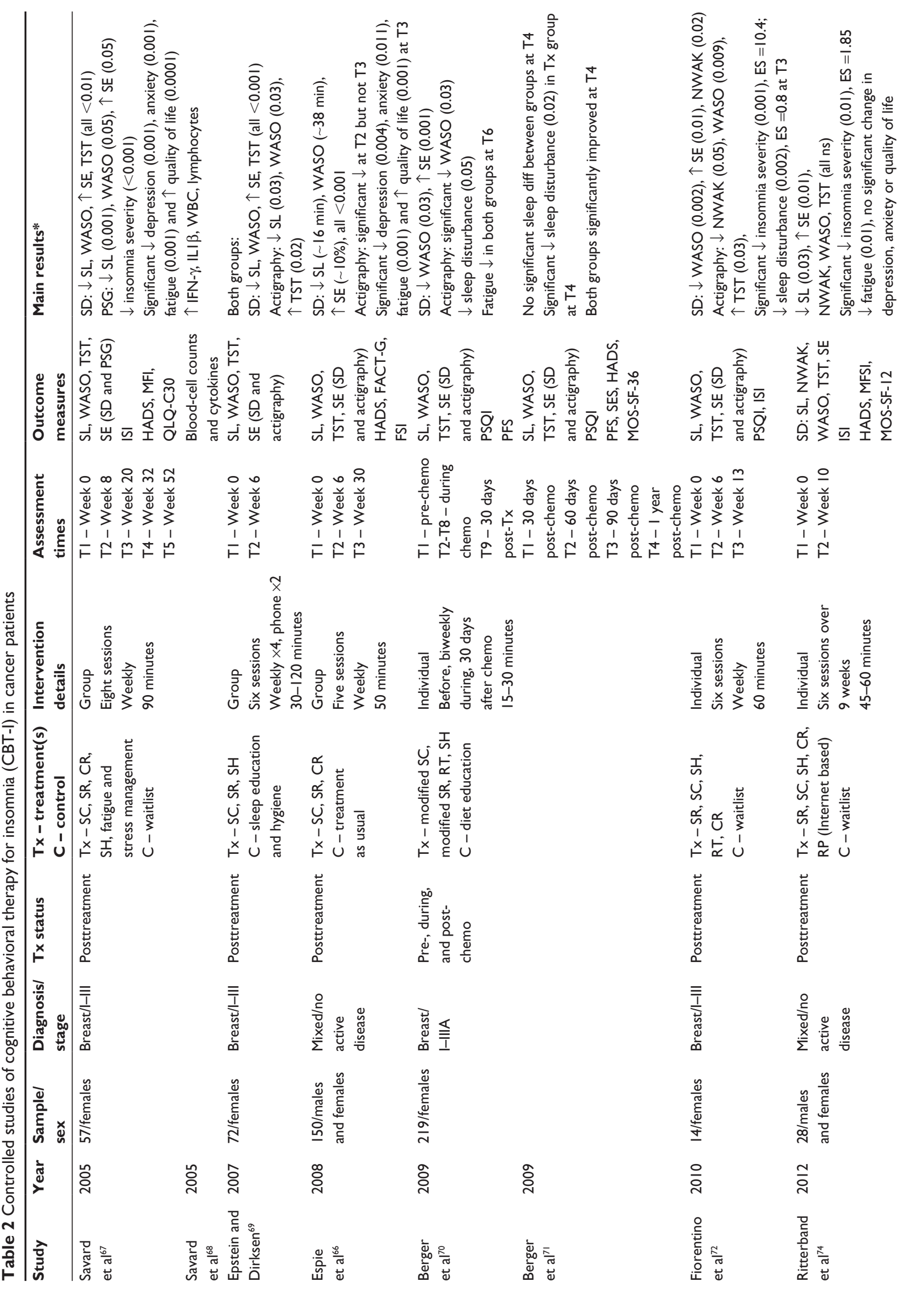



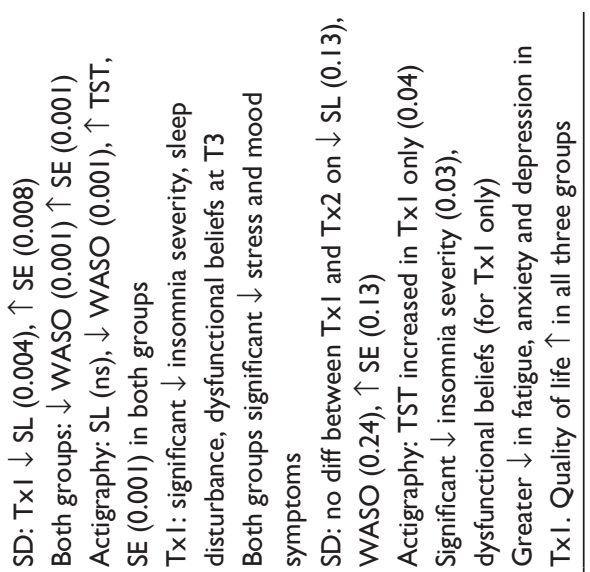

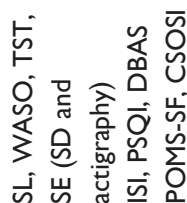

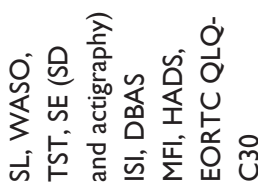

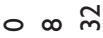

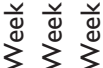

F $\mathrm{F}$
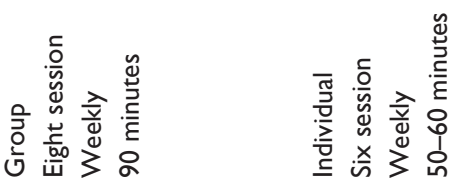

ن $\frac{0}{\sim}$

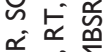

芯

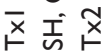

苞

T

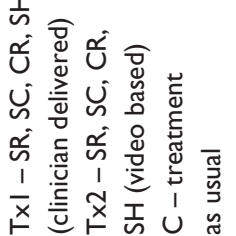

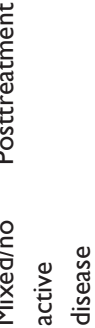

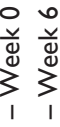

$F F$

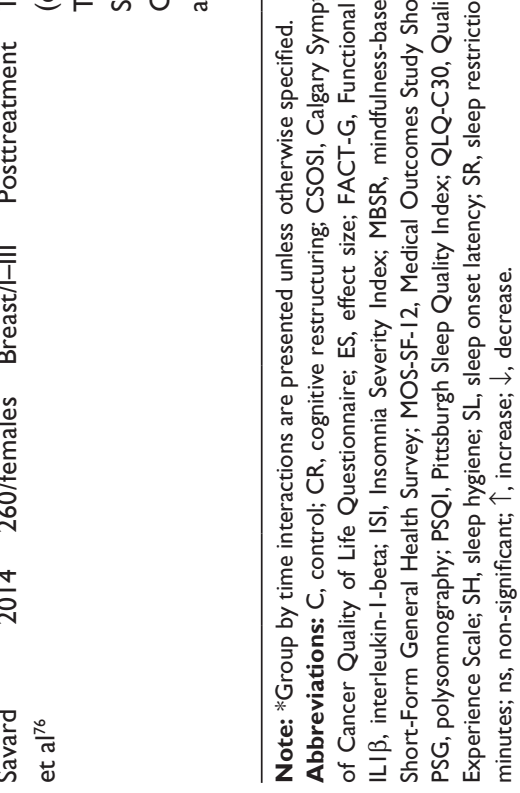

of sleep per night by study completion. The proportion of individuals experiencing clinically significant change was $70 \%$ at 12 -month follow-up. Study participation was also related to some alterations of immune function, as demonstrated by increases in cytokine secretion (interferon gamma and interleukin-1 beta); however, the clinical relevance of these changes remain unclear.

Epstein and Dirksen examined the efficacy of a sixsession CBT intervention for the treatment of insomnia in a sample of breast-cancer survivors. ${ }^{69}$ A total of 72 women were randomized to either CBT-I or a control group that also received sleep education and information on sleep hygiene. Both groups showed similar decreases in sleep onset latency, wake after sleep onset, and time in bed, and increases in total sleep time, sleep efficiency, and sleep quality after treatment. However, these results may underrepresent the effects of CBT-I given that the control group received recommendations that overlapped with the CBT-I intervention - namely, to establish a regular wake time, reduce time spent in bed, and reserve time in the evening to relax. Regardless, the results suggest that addressing sleep disturbance, even at a low intensity, can produce meaningful improvements for individuals with cancer.

Considering that insomnia symptoms tend to be exacerbated during chemotherapy, Berger et al investigated whether sleep could be improved with an individualized sleep-promotion plan including the CBT-I components of stimulus control, sleep restriction, relaxation therapy, and sleep-hygiene counseling in a group of women undergoing chemotherapy for breast cancer. ${ }^{70,71}$ The women were not required to have disturbed sleep upon enrolling in the trial, and the stimulus control and sleep restriction components were modified to be more lenient than would typically be recommended, because the authors felt this would be easier for participants to adhere to during treatment. Prior to beginning chemotherapy, 219 women were randomly assigned to the treatment group or a healthy-eating control condition. The individual plans were reviewed, revised, and reinforced during chemotherapy; at 30,60, and 90 days after the last chemotherapy treatment; and at 1 year posttreatment. Between-group differences were observed for sleep quality and sleep efficiency, as well as a decrease in the number of awakenings and minutes awake after sleep onset at 30 days posttreatment. Only sleep quality, however, remained significantly improved at the 1-year follow-up. This study is novel in its demonstration that behavioral interventions for sleep can be successfully delivered during chemotherapy treatment. 
Many CBT-I interventions for cancer patients are delivered in group formats, making these a time and costeffective treatment option; however, this format may not suit all patients or may not be available in all settings. Hence, Fiorentino et al conducted a randomized controlled crossover pilot trial to determine the effects of a 6-week individual CBT-I program in 14 breast-cancer survivors. ${ }^{72}$ Patients reported improved insomnia symptom severity and better sleep quality, and decreased total sleep time, wake after sleep onset, and number of awakenings compared with waitlist control. Overall, insomnia was completely resolved in $43 \%$ of the participants and sleep disturbance was resolved in $71 \%$, demonstrating the effectiveness of this individual format.

Given the overall limited availability of CBT-I programs, ${ }^{73}$ Ritterband et al examined whether an Internet-based CBT-I program could improve symptoms of insomnia in a sample of cancer survivors. ${ }^{74} \mathrm{~A}$ sample of 28 men and women were randomized to either an Internet-based CBT-I intervention group or a waitlist control group. Participants in the intervention group were given access to an online program called "Sleep Healthy Using The Internet" (SHUTi) for 9 weeks. ${ }^{75}$ The SHUTi program includes sleep restriction, stimulus control, sleep hygiene, cognitive restructuring, and relapse prevention. Compared with the control group, intervention participants demonstrated significantly greater improvements in insomnia severity, sleep efficiency, sleep onset latency, and sleep quality. The results of this study provide initial feasibility data for using Internet-based CBT-I as a method of improving the provision of evidence-based interventions for cancer survivors who may not have regular access to such programs.

Based on their promising preliminary data presented earlier in this article, Savard et al conducted a three-armed trial comparing video-based and professionally delivered CBT-I to a no-treatment control group in 242 women posttreatment for breast cancer. ${ }^{76}$ Both the video and professionally administered CBT-I groups were associated with significantly greater improvements in diary-measured sleep variables compared with the control; however, the patients in the professionally administered treatment group experienced greater remission rates $(71.3 \%$ versus $44.3 \%)$ and reported larger improvements in overall insomnia severity, dysfunctional sleep beliefs, fatigue, and depression levels than the video group. The findings of this study suggest that while face-to-face administration may be optimal, video-based delivery can also produce clinically meaningful improvements and increases options for patients who may not otherwise have access to professionally delivered treatment.

Considering the evidence for the efficacy of CBT-I in cancer patients, research is moving toward comparative effectiveness trials. Garland et al conducted a randomized non-inferiority trial comparing CBT-I with Mindfulnessbased Cancer Recovery (MBCR), an adaptation of Mindfulness Based Stress Reduction (MBSR) in a heterogeneous sample of 111 posttreatment cancer patients. ${ }^{77} \mathrm{MBSR}$ is an increasingly popular, evidence-based intervention designed to reduce overall distress in cancer patients. ${ }^{78-80}$ Preliminary evidence has shown that MBCR/MBSR participation is also associated with improved sleep outcomes in cancer patients. ${ }^{81-83}$ Using a non-inferiority margin of four points on the Insomnia Severity Index ${ }^{84} \mathrm{MBCR}$ demonstrated inferiority to CBT-I when assessed immediately after the program but was within the non-inferiority margin at the 3-month follow-up. For specific sleep variables, CBT-I produced larger improvements in diary-measured sleep latency and sleep efficiency, but both interventions significantly reduced the amount of time spent awake after sleep onset and increased total sleep time. Significant improvements in symptoms of stress and psychological functioning were also reported, regardless of assigned treatment. Considering that CBT-I was associated with faster effects than MBCR, it remains the treatment of choice for most cancer patients with insomnia. With that in mind, however, MBCR/MBSR should be considered a viable alternative for patients who may be interested in an acceptance-based treatment approach.

\section{Discussion}

This article has reviewed the literature and examined the efficacy of CBT-I in people diagnosed with cancer. Consistent with research in the broader population, CBT-I has been found to be associated with clinically and statistically significant improvements in subjective sleep outcomes in patients with cancer. There is also some evidence to suggest that improving sleep may produce concomitant improvements in mood disturbance, cancer-related fatigue, and overall quality of life. There were a variety of treatment modalities offered, including self-administration by video; professional administration of CBT-I to individuals in person, by telephone or over the Internet; and individual and group programs delivered face-to-face - all of which have the potential to increase patient access to evidence-based treatment. Despite the encouraging findings of this review, there are several limitations and identified priorities for future investigation. 
First, while several of the studies reviewed provide support for the efficacy of face-to-face group-based CBT-I interventions as a method of improving sleep in cancer survivors with insomnia, there is still an identified lack of access to such treatments. ${ }^{73}$ The studies by Savard et al ${ }^{64,76}$ and Ritterband et $\mathrm{al}^{74}$ highlight the potential for self-administered and/or Internet-based interventions to fill in treatment gaps and target underserved populations, but larger implementation trials are needed. Future research should investigate the most effective methods for translating the current evidence for interventions like CBT-I into practice, and investigate policy change to improve access and coverage for behavioral sleep medicine services in cancer care. Considering that insomnia in cancer patients is often chronic once it develops, ${ }^{4}$ it is important to investigate the most appropriate screening, assessment, and intervention schedule to efficiently prevent and treat insomnia in this group.

Second, although CBT-I has demonstrated efficacy in the cancer context, there is a significant proportion of patients who do not consistently adhere to the treatment recommendations. ${ }^{85}$ Given that greater adherence to prescribed treatment regimens (eg, prescribed wake times) is associated with greater improvements in sleep,${ }^{86}$ future research should investigate the potential of motivational enhancement techniques to improve compliance and hence response and remittance rates. Patient preference is another particularly important contributor to patient adherence and outcomes for behavioral interventions like CBT-I, which require a significant investment of time and active participation. Relative to CBT-I, Espie et al suggest that acceptance-based approaches for insomnia might receive greater uptake and result in greater benefit in patients with persistent or complicated insomnia ${ }^{87} \mathrm{MBSR}$, independently or in combination with CBT-I components, may also produce clinically significant improvements in sleep ${ }^{88-90}$ Conclusions regarding patient preference, however, await rigorously designed and adequately powered trials.

Third, all of the reviewed studies were delivered to English-, French-, or German-speaking populations. Efforts are being made to train health professionals and more broadly disseminate behavioral sleep medicine interventions like CBT-I, but this goal has not yet been fully realized.

Finally, in the trials reviewed here, studies with homogeneous cancer groups did not have a treatment advantage over studies that included mixed groups of cancer patients, suggesting that effects may be comparable for early stage cancers, regardless of tumor location. At this stage, research needs to shift focus to determine whether CBT-I - as designed or with modifications - can be successfully delivered to patients with aggressive, complex, or late-stage cancers, in order to expand treatment options for these often overlooked populations. ${ }^{91-93}$

\section{Conclusion}

Insomnia has a profound impact on a cancer patient's quality of life and can add to the symptom burden already exacted by the disease. With the prevalence rates of insomnia higher in cancer patients than in the general population, insomnia treatments that can be delivered in conjunction with traditional cancer treatments are necessary. The research examining CBT-I in patients with cancer suggests that it is a generally acceptable treatment that is both efficacious and durable, both during and after cancer treatment. Future research in this area should focus on expanding the populations of patients studied and translating evidence into clinical practice. It remains a health care priority to expand available treatment options and increase awareness and access to CBT-I in cancer care.

\section{Disclosure}

The authors declare no conflicts of interest in this work.

\section{References}

1. Mathers CD, Loncar D. Projections of global mortality and burden of disease from 2002 to 2030. PLoS Med. 2006;3(11):e442.

2. American Cancer Society. Global Cancer Facts and Figures. 2nd ed. Atlanta, GA: American Cancer Society; 2011. Available from: http://www.cancer.org/Research/CancerFactsFigures/ GlobalCancerFactsFigures/global-cancer-facts-figures-2nd-edition. pdf. Accessed April 2, 2014.

3. Siegel R, Naishadham D, Jemal A. Cancer statistics, 2012. CA Cancer J Clin. 2012;62(1):10-29.

4. Savard J, Ivers H, Villa J, Caplette-Gingras A, Morin CM. Natural course of insomnia comorbid with cancer: an 18-month longitudinal study. J Clin Oncol. 2011;29(26):3580-3586.

5. Palesh OG, Roscoe JA, Mustian KM, et al. Prevalence, demographics, and psychological associations of sleep disruption in patients with cancer: University of Rochester Cancer Center-Community Clinical Oncology Program. J Clin Oncol. 2010;28(2):292-298.

6. Savard J, Morin CM. Insomnia in the context of cancer: a review of a neglected problem. J Clin Oncol. 2001;19(3):895-908.

7. Savard J, Savard MH. Insomnia and cancer: prevalence, nature, and non-pharmacological treatment strategies. Sleep Med Clin. 2013;8: 373-387.

8. Savard J, Simard S, Blanchet J, Ivers H, Morin CM. Prevalence, clinical characteristics, and risk factors for insomnia in the context of breast cancer. Sleep. 2001;24(5):583-590.

9. Engstrom CA, Strohl RA, Rose L, Lewandowski L, Stefanek ME. Sleep alterations in cancer patients. Cancer Nurs. 1999;22(2):143-148.

10. Davidson JR, MacLean AW, Brundage MD, Schulze K. Sleep disturbance in cancer patients. Soc Sci Med. 2002;54(9):1309-1321.

11. American Psychiatric Association (APA). Diagnostic and Statistical Manual of Mental Disorders. 5th ed. Arlington, VA: APA; 2013.

12. Sivertsen B, Krokstad S, Mykletun A, Overland S. Insomnia symptoms and use of health care services and medications: the HUNT-2 study. Behav Sleep Med. 2009;7(4):210-222. 
13. Lis CG, Gupta D, Grutsch JF. The relationship between insomnia and patient satisfaction with quality of life in cancer. Support Care Cancer. 2008;16(3):261-266.

14. Savard J, Liu L, Natarajan L, et al. Breast cancer patients have progressively impaired sleep-wake activity rhythms during chemotherapy. Sleep. 2009;32(9):1155-1160.

15. Miaskowski C, Lee K, Dunn L, et al. Sleep-wake circadian activity rhythm parameters and fatigue in oncology patients before the initiation of radiation therapy. Cancer Nurs. 2011;34(4):255-268.

16. Ancoli-Israel S, Liu L, Marler MR, et al. Fatigue, sleep, and circadian rhythms prior to chemotherapy for breast cancer. Support Care Cancer. 2006;14(3):201-209.

17. Kotronoulas G, Wengström Y, Kearney N. A critical review of women's sleep-wake patterns in the context of neo-/adjuvant chemotherapy for early-stage breast cancer. Breast. 2012;21(2):128-141.

18. Savard MH, Savard J, Caplette-Gingras A, Ivers H, Bastien C. Relationship between objectively recorded hot flashes and sleep disturbances among breast cancer patients: investigating hot flash characteristics other than frequency. Menopause. 2013;20(10): 997-1005.

19. Savard J, Hervouet S, Ivers H. Prostate cancer treatments and their side effects are associated with increased insomnia. Psychooncology. 2013;22(6):1381-1388.

20. Beck SL, Berger AM, Barsevick AM, Wong B, Stewart KA, Dudley WN. Sleep quality after initial chemotherapy for breast cancer. Support Care Cancer. 2010;18(6):679-689.

21. Van Onselen C, Cooper BA, Lee K, et al. Identification of distinct subgroups of breast cancer patients based on self-reported changes in sleep disturbance. Support Care Cancer. 2012;20(10):2611-2619.

22. Bower JE. Behavioral symptoms in patients with breast cancer and survivors. J Clin Oncol. 2008;26(5):768-777.

23. Fiorentino L, Rissling M, Liu L, Ancoli-Israel S. The Symptom Cluster of Sleep, Fatigue and Depressive Symptoms in Breast Cancer Patients: Severity of the Problem and Treatment Options. Drug Discov Today Dis Models. 2011;8(4):167-173.

24. Bower JE, Ganz PA, Irwin MR, Kwan L, Breen EC, Cole SW. Inflammation and behavioral symptoms after breast cancer treatment: do fatigue, depression, and sleep disturbance share a common underlying mechanism? J Clin Oncol. 2011;29(26):3517-3522.

25. Stepanski EJ, Walker MS, Schwartzberg LS, Blakely LJ, Ong JC, Houts AC. The relation of trouble sleeping, depressed mood, pain, and fatigue in patients with cancer. J Clin Sleep Med. 2009;5(2): 132-136.

26. Sharma N, Hansen CH, O'Connor M, et al. Sleep problems in cancer patients: prevalence and association with distress and pain. Psychooncology. 2011;21(9):1003-1009.

27. Mormont MC, Waterhouse J, Bleuzen P, et al. Marked 24-h rest/activity rhythms are associated with better quality of life, better response, and longer survival in patients with metastatic colorectal cancer and good performance status. Clin Cancer Res. 2000;6(8):3038-3045.

28. Mormont MC, Waterhouse J. Contribution of the rest-activity circadian rhythm to quality of life in cancer patients. Chronobiol Int. 2002;19(1): 313-323.

29. Fernández-Mendoza J, Vela-Bueno A, Vgontzas AN, et al. Cognitiveemotional hyperarousal as a premorbid characteristic of individuals vulnerable to insomnia. Psychosom Med. 2010;72(4):397-403.

30. Riemann D, Spiegelhalder K, Feige B, et al. The hyperarousal model of insomnia: a review of the concept and its evidence. Sleep Med Rev. 2010;14(1):19-31.

31. Taylor LM, Espie CA, White CA. Attentional bias in people with acute versus persistent insomnia secondary to cancer. Behav Sleep Med. 2003;1(4):200-212.

32. Harvey AG. A cognitive theory and therapy for chronic insomnia. J Cogn Psychother. 2005;19(1):41-59.

33. Carney CE, Edinger JD, Morin CM, et al. Examining maladaptive beliefs about sleep across insomnia patient groups. J Psychosom Res. 2010;68(1):57-65.
34. Woodley J, Smith S. Safety behaviors and dysfunctional beliefs about sleep: testing a cognitive model of the maintenance of insomnia. J Psychosom Res. 2006;60(6):551-557.

35. Morin CM, Benca R. Chronic insomnia. Lancet. 2012;379(9821): 1129-1141.

36. Perlis ML, Smith MT, Jungquist C, Nowakowski S, Orff H, Soeffing J. Cognitive-behavioral therapy for insomnia. In: Attarian HP, Schuman C, editors. Clinical Handbook of Insomnia. 2nd ed. New York, NY: Humana Press; 2010:281-296.

37. Posner D, Gehrman PR. Sleep hygiene. In: Perlis ML, Aloia M, Kuhn B, editors. Behavioral Treatments for Sleep Disorders: A Comprehensive Primer of Behavioral Sleep Medicine Interventions. London; Burlington, MA; and San Diego, CA: Academic Press; 2010:31-43.

38. Morin CM, Espie CA. Insomnia: A Clinical Guide to Assessment and Treatment. New York, NY: Springer; 2004.

39. Morgenthaler T, Kramer M, Alessi C, et al; American Academy of Sleep Medicine. Practice parameters for the psychological and behavioral treatment of insomnia: an update. An American Academy of Sleep Medicine report. Sleep. 2006;29(11):1415-1419.

40. Mitchell MD, Gehrman P, Perlis M, Umscheid CA. Comparative effectiveness of cognitive behavioral therapy for insomnia: a systematic review. BMC Fam Pract. 2012;13(1):40.

41. Smith MT, Perlis ML, Park A, et al. Comparative meta-analysis of pharmacotherapy and behavior therapy for persistent insomnia. Am J Psychiatry. 2002;159(1):5-11.

42. Espie CA, MacMahon KM, Kelly HL, et al. Randomized clinical effectiveness trial of nurse-administered small-group cognitive behavior therapy for persistent insomnia in general practice. Sleep. 2007; 30(5):574-584.

43. Morin CM, Kowatch RA, Barry T, Walton E. Cognitive-behavior therapy for late-life insomnia. J Consult Clin Psychol. 1993;61(1):137-146.

44. Espie CA, Inglis SJ, Tessier S, Harvey L. The clinical effectiveness of cognitive behaviour therapy for chronic insomnia: implementation and evaluation of a sleep clinic in general medical practice. Behav Res Ther. 2001;39(1):45-60.

45. Morin CM, Mimeault V, Gagné A. Nonpharmacological treatment of late-life insomnia. J Psychosom Res. 1999;46(2):103-116.

46. Morin CM, Vallières A, Guay B, et al. Cognitive behavioral therapy, singly and combined with medication, for persistent insomnia: a randomized controlled trial. JAMA. 2009;301(19):2005-2015.

47. Jacobs GD, Pace-Schott EF, Stickgold R, Otto MW. Cognitive behavior therapy and pharmacotherapy for insomnia: a randomized controlled trial and direct comparison. Arch Intern Med. 2004;164(17):1888-1896.

48. Sivertsen B, Omvik S, Pallesen S, et al. Cognitive behavioral therapy vs zopiclone for treatment of chronic primary insomnia in older adults: a randomized controlled trial. JAMA. 2006;295(24):2851-2858.

49. Wu R, Bao J, Zhang C, Deng J, Long C. Comparison of sleep condition and sleep-related psychological activity after cognitive-behavior and pharmacological therapy for chronic insomnia. Psychother Psychosom. 2006;75(4):220-228.

50. Edinger JD, Wohlgemuth WK, Radtke RA, Marsh GR, Quillian RE. Cognitive behavioral therapy for treatment of chronic primary insomnia: a randomized controlled trial. JAMA. 2001;285(14):1856-1864.

51. Rybarczyk B, Stepanski E, Fogg L, Lopez M, Barry P, Davis A. A placebo-controlled test of cognitive-behavioral therapy for comorbid insomnia in older adults. J Consult Clin Psychol. 2005;73(6): 1164-1174.

52. Edinger JD, Olsen MK, Stechuchak KM, et al. Cognitive behavioral therapy for patients with primary insomnia or insomnia associated predominantly with mixed psychiatric disorders: a randomized clinical trial. Sleep. 2009;32(4):499-510.

53. Morin CM, Colecchi C, Stone J, Sood R, Brink D. Behavioral and pharmacological therapies for late-life insomnia: a randomized controlled trial. JAMA. 1999;281(11):991-999.

54. Jansson M, Linton SJ. Cognitive-behavioral group therapy as an early intervention for insomnia: a randomized controlled trial. J Occup Rehabil. 2005;15(2):177-190. 
55. Verbeek IH, Konings GM, Aldenkamp AP, Declerck AC, Klip EC. Cognitive behavioral treatment in clinically referred chronic insomniacs: group versus individual treatment. Behav Sleep Med. 2006; 4(3):135-151.

56. Bastien CH, Morin CM, Ouellet MC, Blais FC, Bouchard S. Cognitivebehavioral therapy for insomnia: comparison of individual therapy, group therapy, and telephone consultations. J Consult Clin Psychol. 2004;72(4):653-659.

57. Vincent N, Lewycky S. Logging on for better sleep: RCT of the effectiveness of online treatment for insomnia. Sleep. 2009;32(6):807-815.

58. Mimeault V, Morin CM. Self-help treatment for insomnia: bibliotherapy with and without professional guidance. J Consult Clin Psychol. 1999;67(4):511-519.

59. Smith MT, Huang MI, Manber R. Cognitive behavior therapy for chronic insomnia occurring within the context of medical and psychiatric disorders. Clin Psychol Rev. 2005;25(5):559-592.

60. Manber R, Edinger JD, Gress JL, San Pedro-Salcedo MG, Kuo TF, Kalista T. Cognitive behavioral therapy for insomnia enhances depression outcome in patients with comorbid major depressive disorder and insomnia. Sleep. 2008;31(4):489-495.

61. Davidson JR, Waisberg JL, Brundage MD, MacLean AW. Nonpharmacologic group treatment of insomnia: a preliminary study with cancer survivors. Psychooncology. 2001;10(5):389-397.

62. Quesnel C, Savard J, Simard S, Ivers H, Morin CM. Efficacy of cognitive-behavioral therapy for insomnia in women treated for nonmetastatic breast cancer. J Consult Clin Psychol. 2003;71(1):189-200.

63. Howell D1, Oliver TK, Keller-Olaman S, et al; Sleep Disturbance Expert Panel on behalf of the Cancer Journey Advisory Group of the Canadian Partnership Against Cancer. A Pan-Canadian practice guideline: prevention, screening, assessment, and treatment of sleep disturbances in adults with cancer. Support Care Cancer. 2013;21(10): 2695-2706.

64. Savard J, Villa J, Simard S, Ivers H, Morin CM. Feasibility of a selfhelp treatment for insomnia comorbid with cancer. Psychooncology. 2011;20(9):1013-1019.

65. Simeit R, Deck R, Conta-Marx B. Sleep management training for cancer patients with insomnia. Support Care Cancer. 2004;12(3):176-183.

66. Espie CA, Fleming L, Cassidy J, et al. Randomized controlled clinical effectiveness trial of cognitive behavior therapy compared with treatment as usual for persistent insomnia in patients with cancer. $J$ Clin Oncol. 2008;26(28):4651-4658.

67. Savard J, Simard S, Ivers H, Morin CM. Randomized study on the efficacy of cognitive-behavioral therapy for insomnia secondary to breast cancer, part I: Sleep and psychological effects. J Clin Oncol. 2005;23(25):6083-6096.

68. Savard J, Simard S, Ivers H, Morin CM. Randomized study on the efficacy of cognitive-behavioral therapy for insomnia secondary to breast cancer, part II: Immunologic effects. J Clin Oncol. 2005;23(25) 6097-6106.

69. Epstein DR, Dirksen SR. Randomized trial of a cognitive-behavioral intervention for insomnia in breast cancer survivors. Oncol Nurs Forum. 2007;34(5):E51-E59.

70. Berger AM, Kuhn BR, Farr LA, et al. One-year outcomes of a behavioral therapy intervention trial on sleep quality and cancer-related fatigue. J Clin Oncol. 2009;27(35):6033-6040.

71. Berger AM, Kuhn BR, Farr LA, et al. Behavioral therapy intervention trial to improve sleep quality and cancer-related fatigue. Psychooncology. 2009;18(6):634-646.

72. Fiorentino L, McQuaid JR, Liu L, et al. Individual cognitive behavioral therapy for insomnia in breast cancer survivors: a randomized controlled crossover pilot study. Nat Sci Sleep. 2010;2:1-8.

73. Perlis ML, Smith MT. How can we make CBT-I and other BSM services widely available? J Clin Sleep Med. 2008;4(1):11-13.

74. Ritterband LM, Bailey ET, Thorndike FP, Lord HR, Farrell-Carnahan L, Baum LD. Initial evaluation of an Internet intervention to improve the sleep of cancer survivors with insomnia. Psychooncology. 2012;21(7): 695-705.
75. Thorndike FP, Saylor DK, Bailey ET, Gonder-Frederick L, Morin CM, Ritterband LM. Development and Perceived Utility and Impact of an Internet Intervention for Insomnia. E J Appl Psychol. $2008 ; 4(2): 32-42$.

76. Savard J, Ivers H, Savard MH, Morin CM. Is a video-based cognitivebehavioral therapy for insomnia as efficacious as a professionallyadministered treatment in breast cancer? Results of a randomized controlled trial. Sleep. In press.

77. Garland SN, Carlson LE, Stephens AJ, Antle MC, Samuels C, Campbell TS. Mindfulness-based stress reduction compared with cognitive behavioral therapy for the treatment of insomnia comorbid with cancer: a randomized, partially blinded, noninferiority trial. J Clin Oncol. 2014;32(5):449-457.

78. Cramer H, Lauche R, Paul A, Dobos G. Mindfulness-based stress reduction for breast cancer-a systematic review and meta-analysis. Curr Oncol. 2012;19(5):e343-e352.

79. Zainal NZ, Booth S, Huppert FA. The efficacy of mindfulness-based stress reduction on mental health of breast cancer patients: a metaanalysis. Psychooncology. 2013;22(7):1457-1465.

80. Ledesma D, Kumano H. Mindfulness-based stress reduction and cancer: a meta-analysis. Psychooncology. 2009;18(6):571-579.

81. Carlson LE, Garland SN. Impact of mindfulness-based stress reduction (MBSR) on sleep, mood, stress and fatigue symptoms in cancer outpatients. Int J Behav Med. 2005;12(4):278-285.

82. Lengacher CA, Reich RR, Post-White J, et al. Mindfulness based stress reduction in post-treatment breast cancer patients: An examination of symptoms and symptom clusters. J Behav Med. 2012;35(1): $86-94$.

83. Andersen SR, Würtzen H, Steding-Jessen M, et al. Effect of mindfulness-based stress reduction on sleep quality: results of a randomized trial among Danish breast cancer patients. Acta Oncol. 2013;52(2):336-344.

84. Savard MH, Savard J, Simard S, Ivers H. Empirical validation of the Insomnia Severity Index in cancer patients. Psychooncology. 2005;14(6):429-441.

85. Matthews EE, Arnedt JT, McCarthy MS, Cuddihy LJ, Aloia MS. Adherence to cognitive behavioral therapy for insomnia: a systematic review. Sleep Med Rev. 2013;17(6):453-464.

86. Matthews EE, Schmiege SJ, Cook PF, Berger AM, Aloia MS Adherence to cognitive behavioral therapy for insomnia (CBTI) among women following primary breast cancer treatment: a pilot study. Behav Sleep Med. 2012;10(3):217-229.

87. Espie CA, Barrie LM, Forgan GS. Comparative investigation of the psychophysiologic and idiopathic insomnia disorder phenotypes: psychologic characteristics, patients' perspectives, and implications for clinical management. Sleep. 2011;35(3):385-393.

88. Ong JC, Ulmer CS, Manber R. Improving sleep with mindfulness and acceptance: a metacognitive model of insomnia. Behav Res Ther. 2012;50(11):651-660.

89. Gross CR, Kreitzer MJ, Reilly-Spong M, et al. Mindfulness-based stress reduction versus pharmacotherapy for chronic primary insomnia: a randomized controlled clinical trial. Explore (NY). 2011; $7(2): 76-87$.

90. Winbush NY, Gross CR, Kreitzer MJ. The effects of mindfulness-based stress reduction on sleep disturbance: a systematic review. Explore (NY). 2007;3(6):585-591.

91. Delgado-Guay M, Yennurajalingam S, Parsons H, Palmer JL, Bruera E. Association between self-reported sleep disturbance and other symptoms in patients with advanced cancer. J Pain Symptom Manage. 2011;41(5):819-827.

92. Gibbins J, McCoubrie R, Kendrick AH, Senior-Smith G, Davies AN, Hanks GW. Sleep-wake disturbances in patients with advanced cancer and their family carers. J Pain Symptom Manage. 2009;38(6): 860-870.

93. Parker KP, Bliwise DL, Ribeiro M, et al. Sleep/Wake patterns of individuals with advanced cancer measured by ambulatory polysomnography. J Clin Oncol. 2008;26(15):2464-2472. 


\section{Publish your work in this journal}

Neuropsychiatric Disease and Treatment is an international, peerreviewed journal of clinical therapeutics and pharmacology focusing on concise rapid reporting of clinical or pre-clinical studies on a range of neuropsychiatric and neurological disorders. This journal is indexed on PubMed Central, the 'PsycINFO' database and CAS.

The manuscript management system is completely online and includes a very quick and fair peer-review system, which is all easy to use. Visit http://www.dovepress.com/testimonials.php to read real quotes from published authors.

\footnotetext{
Submit your manuscript here: http://www.dovepress.com/neuropsychiatric-disease-and-treatment-journal
} 